\title{
Pentachlorophenol Removal by Pleurotus Pulmonarius in Submerged Cultures
}

\author{
Daniela Farani de Souza, Silvio Cláudio da Costa, Antonio Sérgio Dacome, Cristina Giatti \\ Marques de Souza, Adelar Bracht and Rosane Marina Peralta* \\ Departamento de Bioquímica; Universidade Estadual de Maringá; 87015-900; Maringá - PR - Brasil
}

\begin{abstract}
Pentachlorophenol (PCP) removal by Pleurotus pulmonarius grown in submerged cultures in the presence and absence of laccase inducers was studied in this work. When PCP was added to a final concentration of $25 \mathrm{mg} \cdot L^{-1}$ in submerged cultures actively producing laccase, 70\% of the PCP was removed after 96 h. The removal of PCP was less than $20 \%$ in the cultures with low laccase activity. The results suggested that laccase played an important role in the biodegradation of PCP by P. pulmonarius and that for bioremediation purposes the fungus must be cultured under the conditions of active laccase production.
\end{abstract}

Key words: laccase, pentachlorophenol, Pleurotus pulmonarius, xenobiotics

\section{INTRODUCTION}

Pentachlorophenol (PCP) has been widely used as a wood preservative and pesticide. PCP is toxic to all life forms due to its ability to make cell membranes permeable to protons, which leads to dissipation of the transmembrane proton gradients and electrical potentials that are required for energy generation in organisms (McAllistter et al., 1996). Over the last two decades, most developed countries have restricted the use of PCP for domestic and agricultural applications because of health and environmental hazards associated with the compound itself and its impurities (e.g. dioxin, furans and hexachlorobenzene). However, after decades of widespread use as a wood preservative, PCP has become an ubiquitous environmental contaminant. PCP is persistent with a half-life of up to 178 and 200 days in soil and water systems, respectively. In Brazil, PCP was used as a wood preservative until 2006. It is currently one of the most common soil and wastewater pollutants in the country.

Common methods for remediating PCPcontaminated materials include land disposal, incineration, soil washing, and chemical extraction. However, these strategies are expensive and do not eliminate the contaminant from the environment. Alternative strategies, such as transformations mediated by bacteria and fungi (bioremediation) and plants (phytoremediation), are gaining more widespread consideration because they can destroy contaminants or convert them into less bioavailable forms.

In recent years, the capability of white rot fungi (WRF) to biodegrade several xenobiotics and recalcitrant pollutants has generated considerable research interest in the area of industrial/

*Author for correspondence: rmperalta@uem.br 
environmental microbiology (Baldrian, 2008; Coelho et al., 2010; Moreira Neto et al., 2009; Sene et al., 2010). WRF are the only microorganisms known to be able to degrade the highly recalcitrant natural polymer lignin (a heterogeneous polyphenolic polymer) because they possess a powerful enzymatic system formed mainly by peroxidases (lignin peroxidase, EC 1.11.1.12 and Mn peroxidase, EC 1.11.1.13) and laccases (EC 1.10.3.2). Since these enzymes are non-specific, they can also attack a wide range of recalcitrant compounds, structurally related to lignin, accumulated in soil and water (Asgher et al., 2008). In relation to the capability to degrade PCP, Phanerochaete chrysosporium is the best studied WRF (Lamar and Dietrich, 1990; Lamar et al., 1990; Ruttimann-Johnson and Lamar, 1996). In principle at least, other WRF could be useful in the degradation of PCP. For example, Trametes versicolor can mineralize $\mathrm{PCP}$, producing pentachloroanisole as intermediate (Ford et al., 2007; Lamar et al., 1992).

Species of the genus Pleurotus are among the easiest mushrooms to cultivate. In contrast to $P$. chrysosporium, the genus Pleurotus expresses ligninolytic systems during its growth phase. These systems are not inhibited by high nitrogen concentrations. Laccase is one of the most important ligninolytic enzyme of the genus and the induction of laccase by phenolic compounds has been well described in several species, including Pleurotus sajor caju (Lo et al., 2001), Pleurotus eryngii (Muñoz et al., 1997), and Pleurotus pulmonarius (Souza et al., 2004).

For bioremediation purposes, one of the most studied species is $P$. ostreatus, which has a high potential to degrade several organic compounds, including polycyclic aromatic hydrocarbons (PAH) and chlorophenols in liquid and solid-state cultures (Bezalel et al., 1996; Zeddel et al., 1993). In addition, Pleurotus pulmonarius is able to decolourize textile industrial dyes under submerged conditions (Zilly et al., 2002) and to degrade atrazine in solid-state cultures (Masaphy et al., 1996). It was also shown that a spent compost of $P$. pulmonarius was able to remove PCP predominantly by biodegradation (Law et al., 2003). However, this PCP biodegradation was actually the result of the combined action of $P$. pulmonarius cells and several kinds of bacteria present in the system. It remains to be shown that $P$. pulmonarius alone is able to remove PCP. This was precisely the main objective of the present study, in which PCP removal by $P$. pulmonarius grown in submerged cultures in the presence and absence of laccase inducers was compared.

\section{MATERIALS AND METHODS}

\section{Organism and culture conditions}

Submerged cultures of Pleurotus pulmonarius (CCB19) obtained from the Culture Collection of the São Paulo Botany Institute were obtained by transferring three disks from the growing edge of the mycelium on PDA plates to a $250 \mathrm{~mL}$ Erlenmeyer flask containing $50 \mathrm{~mL}$ of potatodextrose medium. The cultures were incubated at $28^{\circ} \mathrm{C}$ in a rotary shaker at $120 \mathrm{rpm}$ for five days. Homogenized and standardized pellets from 5day-old shaken cultures were obtained, and the pellets were used to evaluate the effect of PCP on $P$. pulmonarius growth, enzyme activity, and PCP removal under submerged conditions. Pellets from potato-dextrose medium were transferred to two types of cultures, non-induced and induced laccase media. In the first, the cultures were carried on $25 \mathrm{~mL}$ of mineral solution (Vogel, 1956) using glucose $\left(10 \mathrm{~g} \cdot \mathrm{L}^{-1}\right)$ and ammonium tartrate $\left(0.86 \mathrm{~g} \cdot \mathrm{L}^{-1}\right)$ as carbon and nitrogen sources (basal medium). In the second condition, corn cob extract rich in phenolic compounds was used as laccase inducer. The corn cob extract was prepared by autoclaving $50 \mathrm{~g}$ of corn cob powder plus $500 \mathrm{~mL}$ of mineral medium for $15 \mathrm{~min}$. The mixture was then filtered and the soluble material was enriched with glucose $\left(10 \mathrm{~g} \cdot \mathrm{L}^{-1}\right)$ and ammonium tartrate $\left(0.86 \mathrm{~g} \cdot \mathrm{L}^{-1}\right)$ (corn cob medium). After five days of cultivation at $120 \mathrm{rpm}$ at $28^{\circ} \mathrm{C}, \mathrm{PCP}$ was added to a final concentration of $25 \mathrm{mg} \cdot \mathrm{L}^{-1}(85 \mu \mathrm{M})$. The $P$. pulmonarius biomass was periodically separated by filtration, and used to estimate the fungal growth in comparison to control cultures without PCP. The effects of PCP on Mn peroxidase and laccase activities were also evaluated by comparing the results with those where no PCP was added.

\section{Determination of $\mathrm{PCP}$ remaining in the culture filtrates and PCP adsorbed in the fungal mycelia \\ The remaining PCP was evaluated in the culture filtrates and in the fungal mycelia. To evaluate the}


amount of PCP sorbed on the fungal mycelia, after filtration, the mycelia were washed with distilled water and immediately frozen at $-20^{\circ} \mathrm{C}$. The material was ground to small particle-size and extracted with ethanol in a $125 \mathrm{~mL}$ flask that was shaken at $120 \mathrm{rpm}$ in an orbital shaker for $2 \mathrm{~h}$. The fungal mycelial extract was obtained by centrifugation at $5000 \mathrm{~g}$ for $15 \mathrm{~min}$. PCP in the samples was analysed by high performance liquid chromatography (HPLC), using a reversed phase R-Sil C18 column $(10 \mu \mathrm{M}, 4.6 \times 250 \mathrm{~mm})$, acetonitrile:water:acetic acid (75:25:0.125) as the mobile phase with a flow rate of $0.7 \mathrm{~mL} \cdot \mathrm{min}^{-1}$, and UV detection at $238 \mathrm{~nm}$. The identification of PCP in the samples was based on the retention time and by spiking the samples with PCP standard. PCP concentrations were determined using calibration curves with peak areas of authentic PCP standards.

\section{Enzyme assays}

The laccase activity was determined using syringaldazine as substrate (Leonowicz and Grzywnowicz, 1981). The Mn peroxidase activity was assayed by following the oxidation of $\mathrm{MnSO}_{4}$ in sodium malonate buffer in the presence of $\mathrm{H}_{2} \mathrm{O}_{2}$ (Wariishi et al., 1992). The lignin peroxidase activity was determined by spectrophotometric measurement at $310 \mathrm{~nm}$ of the $\mathrm{H}_{2} \mathrm{O}_{2}$-dependent veratraldehyde formation from veratryl alcohol (Tien and Kirk, 1984). The enzymatic activity was expressed in international unit (U), defined as the amount of enzyme required to produce $1 \mu \mathrm{mol}$ product per min.

\section{Determination of phenolic contents}

Total phenol content was determined using the Folin-Ciocalteau reagent and expressed as ferulic acid equivalents (Singleton and Rossi, 1965).

\section{Statistical analysis}

The data from the different treatments were compared using paired t-test with a significance level of $\mathrm{p} \leq 0.05$. The experiments were conducted in triplicate. The data are presented as mean \pm standard error. The analyses were conducted using the GraphPad Prism® statistical program pack (Graph Pad Software, San Diego, USA).

\section{Chemicals}

The enzymatic substrates and PCP were obtained from Sigma Chemical Corp. (St Louis, MO). PDA was obtained from Difco Laboratories (Detroit, MI). The solvents used in HPLC analysis were of chromatographic grade and all other reagents were of analytical grade.

\section{RESULTS}

Previous studies have shown that media supplemented with soluble phenolic compounds from corn cob powder increased the capability of $P$. pulmonarius to produce laccase and to decolourize the industrial dyes (Tychanowicz et al., 2004). For this reason, the same strategy was used in this work. As expected, soluble corn cob extract increased the phenolic compound content from 0 mmoles $\cdot \mathrm{L}^{-1}$ (basal medium) to 1.43 mmoles $\cdot \mathrm{L}^{-1}$ (corn cob medium). The addition of soluble corn cob extract slightly increased biomass production, however, without statistical significance $(\mathrm{p}>0.05)$ (Fig. 1A). The addition of corn cob extract significantly improved laccase activity by more than four times (from $26.6 \pm 3.00$ $\mathrm{U} \cdot \mathrm{g}$ dry biomass ${ }^{-1}$ to $116.10 \pm 10.00 \mathrm{U} \cdot \mathrm{g}$ dry biomass $^{-1}$ (Fig 1B), but did not significantly affect the Mn peroxidase activity (Fig. 1C).

No lignin peroxidase activity was observed in any culture filtrates. The addition of PCP inhibited considerably the growth of the fungus in the basal condition (Fig. 1A). On the other hand, PCP caused only a slight inhibition of the fungal growth in the corn cob medium. The presence of PCP increased the laccase activity five fold in basal medium and two fold in corn cob medium (Fig. 1B), but did not affect the Mn peroxidase activity (Fig. 1C). After $96 \mathrm{~h}$ of addition of PCP, about 70 and $20 \%$ of the initial PCP were removed in basal and corn cob media, respectively (Fig. 1D). In both types of cultures, less than $8 \%$ of PCP was found to be sorbed to the fungal mycelium. 

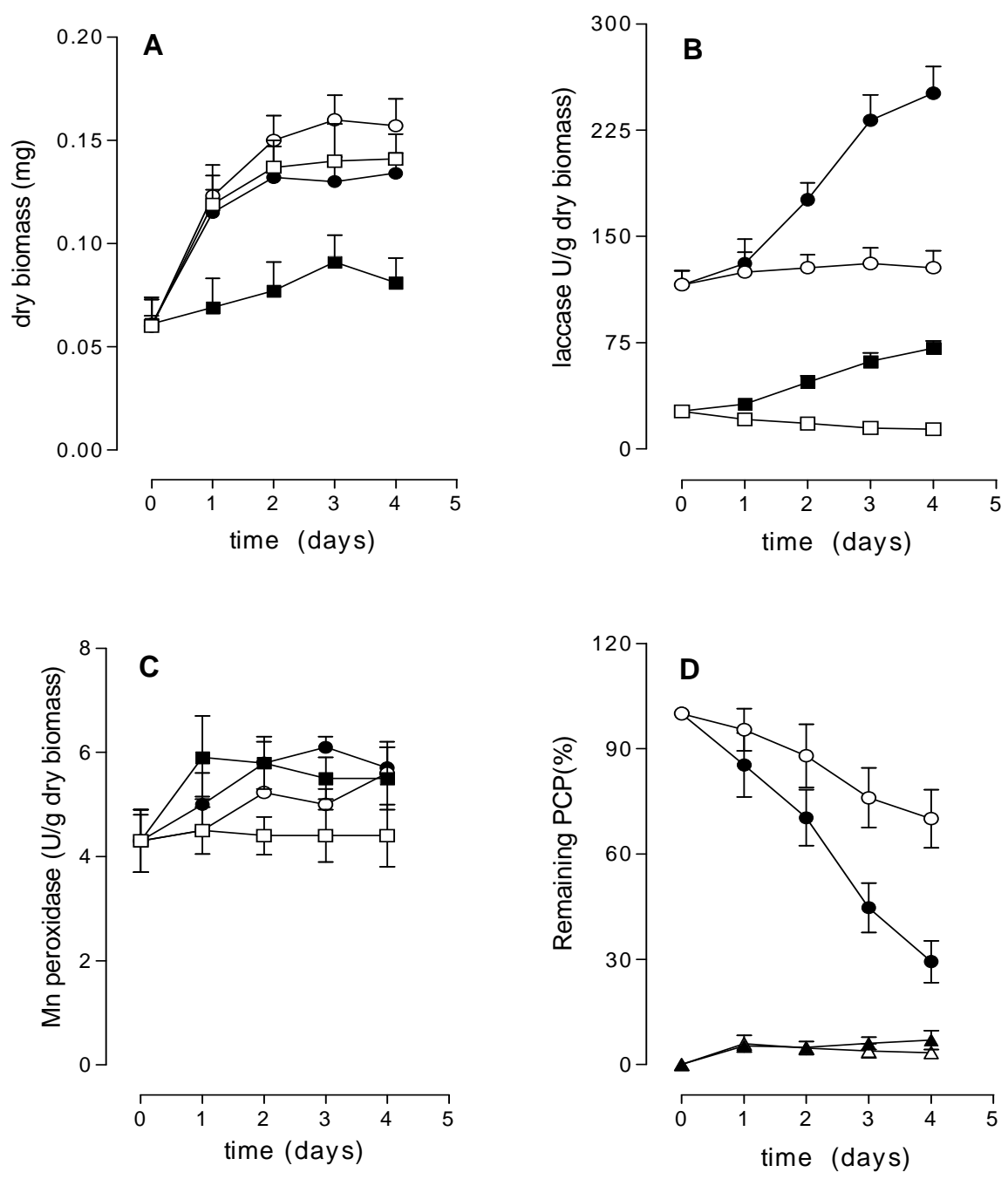

Figure 1 - Effects of PCP in the growth and production of laccase and Mn peroxidase by $P$. pulmonarius. After 5 days of cultivation into basal or corn cob medium, PCP was introduced at the final concentration of $25 \mathrm{mg} \cdot \mathrm{L}^{-1}$. Periodically the cultures were interrupted by filtration. Laccase and Mn peroxidase activities and remaining PCP were determined in the culture filtrates. Dry biomasses were used to estimate the fungal growth and to determine the PCP adsorbed to the mycelia. Legends: $(\bullet)$ induced culture with PCP; (०) induced culture without PCP; (ロ) non-induced culture with PCP; ( $\square$ ) noninduced culture without PCP. In D: $(\boldsymbol{\Delta})$ PCP adsorbed to the mycelial mass obtained in corn cob medium (with laccase inducers); $(\Delta)$ PCP adsorbed to the mycelial mass in basal cultures (without laccase inducers). Each marker and error bar represents the mean and standard deviation of three replicates.

\section{DISCUSSION}

An increasing range of white rot fungi is being investigated for their bioremediation potential. Xenobiotic removal by some white-rot species such as Pleurotus, Ganoderma and Coriolus is believed to be catalyzed mostly by laccases. On the other hand, the oxidation of xenobiotics by other white-rot fungi such as Nematoloma frowardii (Hofrichter et al., 1998), $P$. chrysosporium (Moen and Hammel, 1994), Irpex lacteus (Baboravá et al., 2006) and Bjerkandera sp (Eibes et al., 2007) is mainly due to the action of Mn peroxidases. The data obtained in this work showed that laccase was the main ligninolytic enzyme produced by $P$. pulmonarius in submerged cultures, considering that low Mn peroxidase activities and no lignin peroxidase were detected 
in the culture filtrates. In the genus Pleurotus, laccases are constitutively produced in small amounts; however, their production can be considerably enhanced by a wide variety of substances, mainly aromatic or phenolic compounds related to lignin or lignin derivatives, such as ferulic acid, 2,5 xylidine, $p$-anisidine or veratryl alcohol (Leonowicz et al., 2001; Souza et al., 2004; Tychanowicz et al., 2006)

In this work, the supplementation of submerged cultures with corn cob extract had a very pronounced effect on the laccase activity in $P$. pulmonarius. The laccase inducer effect of the soluble plant extract is considered to be related to its phenolic content. Cotton stalk extract, for example, acted as an inducer of laccase in Pleurotus ostreatus submerged cultures (Ardon et al., 1996; 1998). However, this effect was not a general one, considering that the same extract did not stimulate the production of laccase by $G$. applanatum, T. versicolor and $R$. solani (Ardon et al., 1996).

Another important observation of the present work was that $P$. pulmonarius was resistant to PCP, especially when a high laccase activity was present. Results of this study also showed that PCP increased laccase activity in submerged cultures with $P$. pulmonarius, but had no effect on $\mathrm{Mn}$ peroxidase activity. It has been suggested that laccases may be important aromatic compound detoxification enzymes for many fungal species by catalyzing nonspecific oxidation and polymerization reactions. For example, laccase production was stimulated by the addition of 0.5 mM PCP to liquid cultures of Trametes versicolor (Mougin et al., 2002) and by the addition of $25 \mu \mathrm{M}$ paraquat to $T$. versicolor and $20 \mu \mathrm{M}$ paraquat to A. biennis cultures (Jaszek et al., 2006).

\section{CONCLUSIONS}

Environmental contamination with PCP and other aromatic pollutants are a serious concern worldwide. Many studies have shown that these persistent compounds can be degraded by the ligninolytic system of white-rot fungi. In this study, it was discovered that PCP could be rapidly removed in submerged cultures of $P$. pulmonarius, particularly under culture conditions with high laccase activity. Further studies are necessary to elucidate the types and toxicity of reaction products produced under these conditions. Such studies are important for developing effective bioremediation programs based on the ligninolytic system of $P$. pulmonarius.

\section{ACKNOWLEDGMENTS}

This study was supported by grants from Conselho Nacional de Pesquisa e Desenvolvimento (CNPq), Fundo Paraná and Fundação Araucária. RM Peralta and A. Bracht are research fellow of CNPq. We thank A Chaves and MAF Costa for their technical assistances.

\section{REFERENCES}

Ardon, O.; Kerem, Z.; Hadar, Y. (1996), Enhancement of laccase activity in liquid cultures of the ligninolytic fungus Pleurotus ostreatus by cotton stalk extract. $J$. Biotechnol., 51, 201-207.

Ardon, O.; Kerena, Z.; Hadar, Y. (1998), Enhancement of lignin degradation and laccase activity in Pleurotus ostreatus. Can. J. Microbiol., 44, 670-680.

Asgher, M.; Bhatti, H.N.; Ashraf, M.; Legge, R.L. (2008), Recent developments in biodegradation of industrial pollutants by white-rot fungi and their enzyme system. Biodegradation, 19, 771-783

Baboravá, P.; Moder, M.; Baldrian, P.; Cajthamlová, K.; Cajthaml, T. (2006), Purification of a new manganese peroxidase of the white-rot fungus Irpex lacteus and degradation of polycyclic aromatic hydrocarbons by the enzyme. Chemosphere, 43, 67182

Baldrian, P. (2008), Wood-inhabiting ligninolytic basidomycetes in soils: ecology and constraints for applicability in bioremediation. Fungal Ecol., 1, 4-12

Bezalel, L.; Hadar, Y.; Cerniglia, C.E. (1996), Mineralization of polycyclic aromatic hydrocarbons by the white-rot fungus Pleurotus ostreatus. Appl. Environ. Microbiol., 62, 292-295

Coelho, J.S.; Souza, C.G.M.; Oliveira, A.L.; Bracht, A.; Costa, M.A.F.; Peralta, R.M. (2010), Comparative removal of bentazon by Ganoderma lucidum in liquid and solid state cultures. Curr. Microbiol., 60, 350-355

Eibes, G.; Moreira, M.T.; Feijoo, G.; Daugulis, A.J.; Lema, J.M. (2007), Operation of a two-phase partitioning bioreactor for the oxidation of anthracene by the enzyme manganese peroxidase Chemosphere, 66, 744-1751

Farnet, A-M.; Tagger, S.; Petit, J.L. (1999), Effects of copper and aromaric inducers on the laccases of the white-rot fungus Marasmius quercophilus. Plant. Biol. Pathol., 322, 499-503. 
Ford, C.I.; Walter, M.; Northcott, G. (2007), Fungal inoculum properties: extracellular enzyme expression and pentachlorophenol removal in highly contamined field soils. J. Environ. Qual., 36, 1599-1608

Hofrichler, M.; Scheibner, K.; Schneegab, K.; Fritsche, W. (1998), Enzymatic combustion of aromatic and aliphatic compounds by manganese peroxidase from Nematoloma frowardii. Appl. Environ. Microbiol., 64, 399-404

Jaszek, M.; Grzywnowicz, K.; Malarczyk, E.; Leonowicz, A. (2006), Enhanced extracellular laccase activity as a part of the response system of white rot fungi: Trametes versicolor and Abortiporus biennis to paraquat-caused oxidative stress conditions. Pestic. Biochem. Phys., 85, 147-154

Lamar, R.T.; Dietrich, D.M. (1990), Use of lignindegrading fungi in the disposal of pentachlorophenol treated wood. J. Ind. Microbiol., 9, 181-191

Lamar, R.T.; Dietrich, D.M. (1992), Use of lignindegrading fungi in the disposal of pentachlorophenoltreated wood. J. Ind. Microbiol., 9, 181-191

Lamar, R.T.; Glaser, J.A.; Kirk, T.K. (1990). Fate of pentachlorophenol (PCP) in sterile soils inoculated with the white-rot basidiomycete Phanerochaete chrysosporium: mineralization, volatilisation and depletion of PCP. Soil Biol. Biochem., 22, 433-440

Law, W.M.; lau, W.N.; Lo, K.L.; Wai, L.M.; Chiu, S.W. (2003), Removal of biocide pentachlorophenol in water system by the spent mushroom compost of Pleurotus pulmonarius. Chemosphere, 52, 1531-1537

Leonowicz, A.; Cho, N.-S.; Luterek, J.; Wilkolazka, A.; Wotjas-Wasilewska, M.; Matuszewska, A., Hofrichter, M.; Wesenberg, D.; Rogalski, J. (2001), Fungal laccase: properties and activity on lignin. $J$. Bas. Microbiol., 41, 185-227.

Leonowicz, A.; Grzywnowicz, K. (1981), Quantitative estimation of laccase forms in some white-rot fungi using syringaldazine as a substrate. Enz. Microb. Technol., 3, 55-58.

Lo, A.S.C.; Ho, Y.S.; Buswell, J.A. (2001), Effect of phenolic monomers on the production of laccases by the edible mushroom Pleurotus sajor-caju and partial characterization of a major laccase component. Mycologia, 93, 413-421.

Masaphy, S., Levanon, D., Henis, Y. (1996), Degradation of atrazine by the lignocellulosic fungus Pleurotus pulmonarius during solid-state fermentation. Biores. Technol. 56, 207-214

McAllister, K.A.; Lee, H.; Trevors, J.T. (1996), Microbial degradation of pentachlorophenol. Biodegradation, 7, 1-40.

Moen, M.A.; Hammel, K.E. (1994), Lipid peroxidation by the manganese peroxidase by Phanerochaete chrysosporium is the basis for phenanthrene oxidation by the intact fungus. Appl. Environ, Microbio., 60, 1956-1961
Moreira Neto, S.L.; Matheus, D.R.; Machado, K.M.G. (2009), Influence of $\mathrm{pH}$ on the growth, laccase activity and RBBR decolorization by tropical basidiomycetes. Braz. Arch. Biol. Technol., 52, 10751082

Mougin, C.; Kollmann, A.; Jolivalt, C. (2002), Enhanced production of laccase in the fungus Trametes versicolor by the addition of xenobiotics. Biotechnol Lett., 24, 139-142

Muñoz, C.; Guillen, F.; Martinez, A.T.; Martinez, M.J. (1997), Induction and characterization of laccase in the ligninolytic fungus Pleurotus eryngii. Curr. Microbiol., 34, 1-5

Rüttimann-Johnson, C.; Lamar, R.T. (1996), Polymerization of pentachlorophenol and ferulic acid by fungal extracellular lignin-degrading enzymes. Appl. Environ. Microbiol., 62, 3890-3893

Sene, L.; Converti, A.; Secchi, G.A.R.; Simão, R.C.G. (2010), New aspects on atrazine biodegradation. Braz. Arch. Biol. Technol., 53, 487-496

Singleton,V.L.; Rossi, J.A. Jr., (1965). Colorimetric of total phenolics with phosphomolybdicphosphotungstic acid reagents. Am. J. Eno.Viticul., 16, 144-158

Souza, C.G.M.; Tychanowicz, G.K.; Souza, D.F.; Peralta, R.M. (2004), Production of laccase isoforms by Pleurotus pulmonarius in response to presence of phenolic and aromatic compounds. J. Bas. Microbiol., 2, 129-136

Tien, M.; Kirk, T.K. (1984), Lignin-degrading enzyme from Phanerochaete chrysosporium: purification, characterization and catalytic properties of a unique $\mathrm{H}_{2} \mathrm{O}_{2}$-requiring oxygenase Proc. Nat. Acad. Sci. USA, 81, 2280-2284

Tychanowicz, G.K.; Souza, D.F.; Souza, C.G.M.; Kadowaki, M.K.; Peralta, R.M. (2006), Copper improves the production of laccase by the white-rot

fungus Pleurotus pulmonarius in solid state fermentation. Braz. Arch. Biol. Technol., 49, 699-704

Vogel, H.A. (1956), A convenient growth medium for Neurospora crassa. Microb. Genet. Bull., 13, $42-43$

Wariishi, H.; Valli, K.; Gold, M.H. (1992), Manganese (II) oxidation by manganese peroxidase from the basidiomycete Phanerochate chrysosporium. J. Biol. Chem., 267, 23688-23695

Zeddel, A.; Majcherczyk, A.; Hüttermann, A. (1993), Degradation of polychlorinated biphenyls by whiterot fungi Pleurotus ostreatus and Trametes versicolor in a solid state system. Toxicol. Environ. Chem., 40, 255-266.

Zilly, A.; Souza, C.G.M.; Peralta, R.M. (2002), Decolorisation of industrial dyes by a Brazilian strain of Pleurotus pulmonarius producing laccase as the sole phenol-oxidizing enzyme. Folia Microbiol., 47, 273-277 